Capacitively coupled hydrogen plasmas sustained by tailored voltage waveforms: vibrational kinetics and negative ions control

This content has been downloaded from IOPscience. Please scroll down to see the full text.

Download details:

IP Address: 131.155.2.68

This content was downloaded on 27/05/2017 at 00:29

Manuscript version: Accepted Manuscript

Diomede et al

To cite this article before publication: Diomede et al, 2017, Plasma Sources Sci. Technol., at press: https://doi.org/10.1088/1361-6595/aa752c

This Accepted Manuscript is: (c) 2017 IOP Publishing Ltd

During the embargo period (the 12 month period from the publication of the Version of Record of this article), the Accepted Manuscript is fully protected by copyright and cannot be reused or reposted elsewhere.

As the Version of Record of this article is going to be / has been published on a subscription basis, this Accepted Manuscript is available for reuse under a CC BY-NC-ND 3.0 licence after the 12 month embargo period.

After the embargo period, everyone is permitted to copy and redistribute this article for non-commercial purposes only, provided that they adhere to all the terms of the licence https://creativecommons.org/licences/by-nc-nd/3.0

Although reasonable endeavours have been taken to obtain all necessary permissions from third parties to include their copyrighted content within this article, their full citation and copyright line may not be present in this Accepted Manuscript version. Before using any content from this article, please refer to the Version of Record on IOPscience once published for full citation and copyright details, as permission will likely be required. All third party content is fully copyright protected, unless specifically stated otherwise in the figure caption in the Version of Record.

When available, you can view the Version of Record for this article at: http://iopscience.iop.org/article/10.1088/1361-6595/aa752c 


\title{
Capacitively coupled hydrogen plasmas sustained by tailored voltage waveforms: vibrational kinetics and negative ions control
}

\author{
P. Diomede ${ }^{1, \text { a }}$, B. Bruneau ${ }^{2}$, S. Longo ${ }^{3,4}$, E. Johnson², J.-P. Booth ${ }^{5}$ \\ ${ }^{1}$ DIFFER - Dutch Institute for Fundamental Energy Research, De Zaale 20, 5612 AJ Eindhoven, The \\ Netherlands \\ ${ }^{2}$ LPICM-CNRS, Ecole Polytechnique, 91128 Palaiseau, France \\ ${ }^{3}$ Dipartimento di Chimica, Universita’ degli Studi di Bari, via Orabona 4, 70126 Bari, Italy \\ ${ }^{4}$ CNR Nanotec, Via Amendola 122/D, 70126, Bari, Italy \\ ${ }^{5}$ LPP, Ecole Polytechnique-CNRS-Univ Paris-Sud-UPMC, 91128 Palaiseau, France \\ acorresponding author: p.diomede@differ.nl
}

\begin{abstract}
A comprehensive hybrid model of a hydrogen capacitively coupled plasmas (CCP), including a detailed description of the molecular vibrational kinetics, has been applied to the study of the effect of tailored voltage waveforms (TVWs) on the production kinetics and transport of negative ions in these discharges. Two kinds of TVWs are considered, valleys-to-peaks and saw-tooth, with amplitude and slope asymmetry respectively. By tailoring the voltage waveform only, it is possible to exert substantial control over the peak density and/position of negative ions inside the discharge volume. This control is particularly effective for saw-tooth waveforms. Insight into the mechanisms allowing this control is provided by an analysis of the model results. This reveals the roles of the vibrational distribution function and of the electron energy distribution and their correlations, as well as changes in the negative ion transport in the electric field when using different TVWs. Considering the chemical reactivity of $\mathrm{H}^{-}$ions, the possibility of a purely electrical control of the negative ion cloud in a reactor operating with a feedstock gas diluted by hydrogen may find interesting applications. This is the first study of vibrational kinetics in the context of TVWs in molecular gases.
\end{abstract}

Keywords: tailored voltage waveforms, electrical asymmetry effect, capacitively coupled plasmas, hydrogen, hybrid model, vibrational kinetics, negative ion production 


\section{Introduction}

Capacitively coupled plasmas (CCPs) in gas mixtures rich in hydrogen are routinely used in material processing due to the beneficial effects of hydrogen atoms. In particular, they are used for the deposition of carbon and silicon based materials and for thin film etching.

In these applications ionic and radical species like $\mathrm{H}_{2}{ }^{+}$and $\mathrm{H}$ are known to play an important role. There is also considerable interest in the role of negative ions which are also present in these discharges [1].

Since negative ions are easily neutralized (with an ionization potential of $0.75 \mathrm{eV}$ ), they are very interesting as a charged carrier of neutral hydrogen, as an alternative to $\mathrm{H}^{+}$ions which release $13.6 \mathrm{eV}$ per neutralization reaction. Negative hydrogen ions are already actively used, thanks to the above mentioned very low ionization energy, as intermediate species for the production of fast hydrogen atom beams in nuclear fusion experiments [2, 3].

Negative hydrogen ions are not formed directly from ground-state hydrogen molecules, but via vibrational excitation of hydrogen molecules by electron impact $[4,5]$. This complex kinetics has been studied mostly in inductively coupled/multipole and post-discharge plasmas purposely developed for optimal negative ion production (e. g. [6 - 8]); much less work has been done on capacitively coupled devices, with the exception of a few studies $[1,9,10]$. One of the reasons for the lack of attention given to $\mathrm{H}^{-}$ions in the context of materials processing is that negative hydrogen ions tend to be confined to the discharge centre by the average plasma potential well and do not reach the surfaces.

Negative ions are produced in the pre-sheath regions where the product of electron density by the production rate coefficients is maximal. Subsequently negative ions flow towards the potential energy bottom in the centre of the plasma.

This behaviour, however, could be possibly controlled by taking advantage of the plasma asymmetry created using tailored voltage waveforms (TVWs) [11, 12].

In this perspective, the possibility of controlling the position of the negative ion peak by changing only the voltage waveform, combined with the special chemical properties of negative hydrogen ions, could revise our view of hydrogen as an electronegative gas.

In this paper we employ a code well-validated against other models [13] and experiments [14 - 18] to a first exploration of this possibility. The challenge is to take into account the effect of the TWVs induced asymmetry on the vibrational distribution. 
To our knowledge, this is the first paper where the effect of the TVWs on the kinetics of vibrationally excited states, and on subsequent negative ion production is studied. Only a hybrid model, such as that presented here, is capable of treating this problem, combining a state-to-state reaction-diffusion model to describe the kinetics of neutral particles, with a Particle in Cell with Monte Carlo Collision (PIC/MCC) model to describe the charged particles. Previous experimental and computational investigations of CCPs driven by two consecutive harmonics with adjustable phase in $\mathrm{H}_{2}$ have been performed by Schüngel and Mohr et al. [19 - 21], but were focused on the spatio-temporal dynamics and ion fluxes and ion fluxes energy distributions at the electrodes and the model adopted did not include the vibrational kinetics, essential to determine negative ions profiles. Also, some of the present authors have performed experimental and computational studies of CCPs in hydrogen driven by TVWs with a sum of up to 5 harmonics $[15,18]$, but still focused on the spatio-temporal dynamics and ion fluxes and energy distribution. Other studies of CCPs driven by TVWs in electronegative gases (e.g. [22 - 24]) have been carried out, but did not consider the possibility of negative ions control.

\section{Numerical model}

Numerical simulations were carried out using a one dimensional code for geometrically symmetric parallel plate CCP reactors. This hybrid code has been described previously in detail $[15,16]$. It self-consistently couples a PIC/MCC description for five charged species $\left(\mathrm{H}^{+}, \mathrm{H}_{2}{ }^{+}, \mathrm{H}_{3}{ }^{+}, \mathrm{H}^{-}\right.$and electrons) with a state-to-state reaction-diffusion fluid model for neutrals (15 vibrational levels of the electronic ground state of $\mathrm{H}_{2}$, and $\mathrm{H}$ atoms). The equations of motion for the charged particles are integrated by using the leap-frog method and the electric field is calculated by solving the Poisson equation, with the space charge obtained from a first-order particle-grid interpolation. The field equation is solved after each PIC time step $\Delta t$ using a finite difference method as shown in [25]. However, since the pressure considered is relatively high, we do not assume the same fixed time step to account for random collisions of particles; instead, a random sequence of flight times is generated based on their exact statistics using the null collision Monte Carlo (MC) method [26, 27]. The MC method used for the ions takes into account the thermal speed of neutral species as shown in [28] which is important for describing $\mathrm{H}^{-}$ions which may decelerate almost to thermal speed without reacting. Concerning chemical reactions, reaction sets for neutral and charged particles are reported in Table 1 and 2, respectively. In particular, for $\mathrm{H}^{-}$we consider the 
production by dissociative attachment of electrons to vibrationally excited molecules, recombination with positive ions and detachment losses. The acceleration scheme for negative ions kinetics described in [14] has not been used since the approximations involved, although appropriate for the previous studies, make it not accurate for the higher plasma density conditions in the present results.

Table 1. Reactions included in the chemical kinetics for neutral particles.

Reaction

$\mathrm{e}+\mathrm{H}_{2}(\mathrm{v}=0) \rightarrow \mathrm{e}+\mathrm{H}_{2}(\mathrm{v}=1, \ldots, 5)$

$\mathrm{e}+\mathrm{H}_{2}(\mathrm{v}=1, \ldots, 5) \rightarrow \mathrm{e}+\mathrm{H}_{2}(\mathrm{v}=0)$

$\mathrm{H}_{2}(\mathrm{v})+\mathrm{H}_{2}(\mathrm{w}) \rightarrow \mathrm{H}_{2}(\mathrm{v}-1)+\mathrm{H}_{2}(\mathrm{w}+1)$

$\mathrm{H}_{2}(\mathrm{v})+\mathrm{H}_{2} \rightarrow \mathrm{H}_{2}(\mathrm{v}-1)+\mathrm{H}_{2}$

$\mathrm{H}_{2}(\mathrm{v})+\mathrm{H}_{2} \rightarrow \mathrm{H}_{2}(\mathrm{v}+1)+\mathrm{H}_{2}$

$\mathrm{H}_{2}(\mathrm{v})+\mathrm{H} \rightarrow \mathrm{H}_{2}(\mathrm{w})+\mathrm{H}$

$\mathrm{e}+\mathrm{H}_{2} \rightarrow \mathrm{e}+2 \mathrm{H}$

$\left(\right.$ via $\left.b^{3} \Sigma_{\mathrm{u}}^{+}, c^{3} \Pi_{\mathrm{u}}, a^{3} \Sigma_{\mathrm{g}}{ }^{+}, d^{3} \Pi_{\mathrm{u}}\right)$

$\mathrm{e}+\mathrm{H}_{2}(\mathrm{v}) \rightarrow \mathrm{e}+\mathrm{H}_{2}(\mathrm{w})$

(via $\mathrm{B}^{1} \Sigma_{\mathrm{u}}^{+}, \mathrm{C}^{1} \Pi_{\mathrm{u}}$ )

$\mathrm{e}+\mathrm{H}_{2} \rightarrow \mathrm{e}+\mathrm{H}+\mathrm{H}(\mathrm{n}=2-3)$

$\mathrm{e}+\mathrm{H}_{2} \rightarrow \mathrm{H}+\mathrm{H}^{+}+2 \mathrm{e}$

$\mathrm{e}+\mathrm{H}_{2} \rightarrow \mathrm{H}_{2}^{+}+2 \mathrm{e}$

$\mathrm{H}_{2}{ }^{+}+\mathrm{H}_{2} \rightarrow \mathrm{H}_{3}{ }^{+}+\mathrm{H}$ (fast)

$\mathrm{H}_{2}(\mathrm{v}>0)$ - wall $\rightarrow \mathrm{H}_{2}(\mathrm{v}=0)$

$\mathrm{H}-$ wall $\rightarrow 1 / 2 \mathrm{H}_{2}(\mathrm{v}=0)$

$\mathrm{e}+\mathrm{H} \rightarrow 2 \mathrm{e}+\mathrm{H}^{+}$

$\mathrm{e}+\mathrm{H}_{2}(\mathrm{v}=0, \ldots, 14) \rightarrow \mathrm{H}+\mathrm{H}^{-}$
Name

$\mathrm{eV}$ processes

Mono-quantum VV energy exchange

Mono-quantum $\mathrm{H}_{2}(\mathrm{v}) / \mathrm{H}_{2}$

VT energy exchange

Multi-quantum $\mathrm{H} / \mathrm{H}_{2}(\mathrm{v})$

VT energy exchange

$\mathrm{H}_{2}(\mathrm{X})$ dissociation

through triplet states

EV processes

Dissociation to

excited atoms

Mixed atom/ion channels

$\mathrm{H}_{2}(\mathrm{y})$ deactivation

on surfaces

Atom recombination

on surfaces

Atom ionization

Dissociative attachment
Ref.

[29]

[30]

[30]

[31]

[29]

[37]

The density for the neutral species $n_{c}$ is obtained by using the Gauss-Seidel method to find a stationary solution for the set of non-linear rate equations with a diffusion term, that in one dimension reads as:

$$
-D_{c} \frac{\partial^{2} n_{c}(x)}{\partial x^{2}}=\sum_{r}\left(v_{r c}^{\prime}-v_{r c}\right) k_{r} \prod_{q} n_{q}^{v_{r q}}
$$


where $D_{c}$ is the diffusion coefficient and $v_{r c}$ is the stoichiometric coefficient of the $c$-th species in the $r$-th elementary process. Primed $\left(v_{r c}^{\prime}\right)$ and un-primed $\left(v_{r c}\right)$ stoichiometric coefficients refer to reaction products and reactants, respectively, $q$ is a generic reactant species. $D_{\mathrm{H}_{2}}$ is taken from Table 25 in [38], $D_{H}$ is estimated from $D_{H_{2}}$ by correcting for the different cross section and reduced mass. Both coefficients are also corrected for the gas pressure $p$ based on a $1 / p$ dependence. The boundary conditions at the two electrode surfaces $x=0$ and $x=d$ are formulated as in [10] taking into account the surface reactivity. This leads to boundary conditions of the form

$D_{c} \frac{\partial n_{c}}{\partial \zeta}=\frac{\gamma}{4(1-\gamma / 2)} \mathrm{v}_{\mathrm{th}} n_{c}-R$

where $\sigma$ is the process related total cross section and $m_{e}$ and $\varepsilon$ are the electron mass and energy. The EEDF is normalized in such a way that the local fraction of electrons with kinetic energy in the range $(\varepsilon, \varepsilon+d \varepsilon)$ is given by $\varepsilon^{1 / 2} f_{e}(\varepsilon, x) d \varepsilon$.

The wall reactions in the fluid model include the deactivation of vibrationally excited molecules (with probability $\gamma_{V}$ ) and the recombination of $\mathrm{H}$ atoms (with a probability $\gamma_{H}$ ).

$\mathrm{H}_{2}(\mathrm{X}, \mathrm{v}>0) \stackrel{\text { surf. }}{\longrightarrow} \mathrm{H}_{2}(\mathrm{X}, \mathrm{v}=0)$ 
$\mathrm{H} \stackrel{\text { surf. }}{\longrightarrow} \frac{1}{2} \mathrm{H}_{2}(\mathrm{X}, \mathrm{v}=0)$.

For the results shown in this paper both vibrational deactivation and atom recombination were assumed to result in molecules in the $\mathrm{v}=0$ vibrational state. A different choice/leads to a slightly more electronegative discharge and a higher population of high vibrational levels [9].

Table 2. Processes included in the PIC/MCC model.

Charged/neutral particle

$\mathrm{e} / \mathrm{H}_{2}$

$\mathrm{e} / \mathrm{H}_{2}(\mathrm{v})$

$\mathrm{e} / \mathrm{H}$

$\mathrm{H}_{3}{ }^{+} / \mathrm{H}_{2}$

$\mathrm{H}_{2}{ }^{+} / \mathrm{H}_{2}$

$\mathrm{H}^{+} / \mathrm{H}_{2}$

$\mathrm{H}^{+} / \mathrm{H}$

$\mathrm{H}^{-} / \mathrm{H}_{2}$

$\mathrm{H}^{-} / \mathrm{H}$

$\mathrm{H}^{-} / \mathrm{H}_{3}^{+}$

\section{Collision}

processes

Elastic scattering

$\mathrm{eV}-\mathrm{EV}$ processes

Electronic excitation

Dissociation

Ionization

Dissociative attachment

Elastic scattering

Vibrational deactivation

Elastic scattering

Direct ionization

Elastic scattering

Conversion to $\mathrm{H}^{+}$

Conversion to $\mathrm{H}_{2}{ }^{+}$

Charge transfer

Conversion to $\mathrm{H}_{3}{ }^{+}$

Elastic scattering

Charge exchange

Elastic scattering

Detachment

Detachment

Charge exchange

Neutralization
Ref.

[29]

[29, 32]

[29]

[29]

[29]

[37]

[29]

[29]

[29]

[29]

[33]

[33]

[33]

[33]

[33]

[40]

[39]

[40]

The predictions of this code were recently compared to experimental results in the case of TVWs [15]. The simulated Ion Flux Distribution Functions (IFDFs) were shown to be in good agreement with those measured experimentally with a Quadrupole Mass Spectrometer (QMS) coupled with an ion energy analyser. Also, the predictions of this hybrid model were compared to phase resolved optical emission spectroscopy (PROES) measurements $[17,18]$, giving again a good agreement. 


\section{Results}

As in ref. [18], for all test cases, the inter-electrode gap $d$ was set to $2.5 \mathrm{~cm}$, the gas pressure was $900 \mathrm{mTorr}$ and the gas temperature $300 \mathrm{~K}$. The fundamental frequency of the applied voltage was increased to $13.56 \mathrm{MHz}$ with respect to [18], where it was set to $5 \mathrm{MHz}$, but in this work results at $5 \mathrm{MHz}$ were also considered for comparison. The electrode at $x=0$ was powered, the one at $x=d$ was grounded. As far as surface processes are concerned, the probability of secondary electron emission by ion impact was 0.1 [41], the atom recombination probability on the walls was 0.1 , and the vibrational deactivation probability 0.02. Surface coefficients were chosen based on a geometrical average of values found in literature (e.g. [34, 35]). The electron sticking coefficient was set to 1. Physical parameters are summarized in Table 3. Depending on the waveform, about 100000 particles were used in the simulations, with 400 grid points for the PIC module, and a time step of $\sim 10^{-11} \mathrm{~s}$, in order to satisfy accuracy/stability criteria [25]. For the neutrals chemical kinetics module, 50 grid points were used. Simulations were executed until steady-state wás reached, which typically took about a few thousand RF cycles, the main bottleneck béing the slow convergence of negative ions.

Table 3: Values for physical parameters in the model

$\begin{array}{ll}T_{g} & 300 \mathrm{~K} \\ p & 900 \mathrm{mTorr} \\ d & 2.5 \mathrm{~cm} \\ f & 13.56 \mathrm{MHz} \text { (or } 5 \mathrm{MHz} \text { ) } \\ \gamma_{V} & 0.02 \\ \gamma_{H} & 0.1 \\ \gamma_{s e c} & 0.1\end{array}$

\section{Amplitude asymmetry}

In this section, waveforms according to Eq. (5) are used,

$V_{A C}(t)=-V_{0} \sum_{k=1}^{n} \frac{n-k+1}{n} \cos (k \omega t+\Theta)$, 
Where $V_{0}$ is a voltage amplitude factor, $n$ is the number of harmonics, $\omega$ is the angular frequency, ( $\omega=2 \pi f$, with $f$ the frequency), and $\Theta$ is a phase shift, in this case the same for all harmonics. $V_{0}$ is set to give the desired peak-to-peak voltage, $V_{P P}$. TVWs therefore contain multiple harmonics of the same fundamental frequency $f$. The harmonics' amplitudes are chosen to maximize the amplitude asymmetry of the waveform (i.e. the ratio of the maximum and the minimum (relative to the temporal average) of the applied voltage waveform) for $\Theta=$ 0 or $\pi$ and, in turn, maximize the range of the DC self-bias caused by the electrical asymmetry effect $[12,42,43])$. For the calculations in this section, $n$ was set to 4 . $V_{0}$ was kept constant at $112 \mathrm{~V}$ (giving a peak-to-peak voltage $V_{P P}=350 \mathrm{~V}$ for $\Theta=0$ ). The phase shift $\Theta$ was varied from 0 to $\pi$ in order to vary the amplitude asymmetry of the waveform from a maximum (for $\Theta=0$ ) to a minimum (for $\Theta=\pi / 2$ ), as shown in Fig. 1. This corresponds to switching from a “valleys" to a "peaks" waveform. This is opposite to that used in ref. [18], where a peaks-tovalleys variation was considered (plus sign in Eq. (5)).

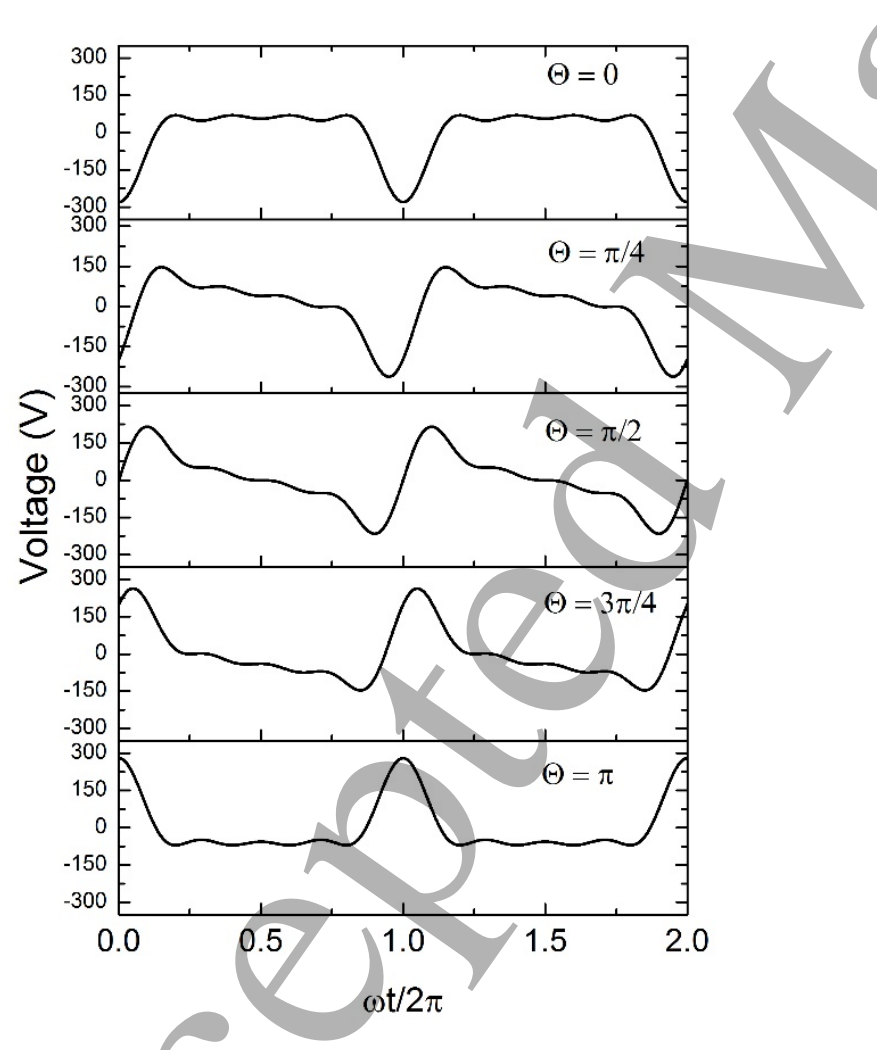

Fig. 1 Voltage waveforms (valleys-to-peaks) for the amplitude asymmetry case: the phase shift $\Theta$ in Eq. (5) is varied, whereas the peak-to-peak voltage is kept constant at $350 \mathrm{~V}$ and the number of harmonics $n$ is 4 . 
In Fig. 2, the time-averaged electron, $\mathrm{H}_{3}{ }^{+}$and $\mathrm{H}^{-}$number densities as a function of position across the discharge gap for different values of the phase shift in the voltage waveform are shown. The variation of the phase shift causes first a decrease of the plasma density up to $\Theta=\pi / 2$, followed by an increase, accompanied by a shift of the maximum towards the powered electrode for $\Theta$ up to $\pi$. $\mathrm{H}^{+}$ions (not shown) exhibit a trend very similar to the one for $\mathrm{H}_{3}{ }^{+}$, but with a number density about an order of magnitude smaller. $\mathrm{H}_{2}{ }^{+}$profiles (also not shown) have a more complicated structure with several peaks in the sheath and pre-sheath regions, whose relative height can be tuned with the phase shift, but their number density is about two orders of magnitude smaller than the one for $\mathrm{H}_{3}{ }^{+}$, therefore they are negligible for the present study.

The negative ion maximum increases and shifts towards the grounded electrode for $\Theta$ up to $\pi / 2$, then decreases and shifts towards the discharge centre for $\Theta=3 \pi / 4$, then increases and shifts towards the powered electrode for $\Theta=\pi$.

The results for $\Theta=\pi$ have a mirror symmetry with respect to the discharge mid-plane compared to results for $\Theta=0$, as it would be expected since a phase shift of $\pi$ swaps the role of the electrodes.

Fig. 4 shows the DC self-bias as a function of the phase shift. As was previously observed for the low frequency case [18], there is an almost linear decrease (passing from positive to negative) from $\Theta=0$ to $\Theta=\pi$, as expected from the theory behind the electrical asymmetry effect and its confirmations [12, 42, 43].

The asymmetry of the discharge has a marked effect upon the production rate of negative ions, which, in particular in the case of hydrogen, is a complex process sensitive to the EEDF and VDF. Fig. 5 displays the time-averaged EEDF (top row) and vibrational distribution function (VDF) (bottom row) as a function of position across the discharge gap for different values of the phase shift in the voltage waveform. The EEDF shows complex behaviour featuring multiple high energy tails variously distributed in space, this distribution being sensitively affected by changing the phase shift. Similarly to what found in [18] for the lower frequency case, a strong field reversal (not shown) occurs close to the electrode where the sheath is expanded for most of the RF cycle (i.e. from $x=d$, for $\Theta=0$ to $x=0$, for $\Theta=\pi$ ). This field reversal causes higher ionization close to this electrode. Due to the role of the socalled high-threshold vibrational excitation (EV) processes through electronically excited singlet states, these changes in the EEDF induce an asymmetric spatial distribution of the 
population of middle vibrational levels, which are the most important for the production of negative ions. The EV processes, described in detail in [9] lead to vibrationally excited molecules in the ground electronic $\mathrm{X}^{1} \Sigma_{\mathrm{g}}{ }^{+}$state via radiative decay from an intermediate electronically excited state $\left(\mathrm{B}^{1} \Sigma_{\mathrm{u}}{ }^{+}\right.$or $\left.\mathrm{C}^{1} \Pi_{\mathrm{g}}\right)$. Despite having a threshold in the range $10-12 \mathrm{eV}$, they represent the most effective vibrational excitation process when high energy electrons are available. This can be seen in Fig. 6, which shows spatial variation of the rate of dissociative attachment for a specific value of $\Theta$. This predominance of $\mathrm{H}^{-}$production via these intermediate levels arises from the vibrational-level dependence of the attachment rate coefficient and the preferential population of those levels, as discussed in [9]. As shown in Fig. 7, the cross section for electron dissociative attachment of $\mathrm{H}_{2}$ molecules increases by orders of magnitude with the vibrational quantum number of target $\mathrm{H}_{2}$ molecules in the $\mathrm{v}$ range 0-5. Since the electron dissociative attachment is a low threshold process, whereas the $\mathrm{EV}$ is a high threshold process, the rate of negative ion production is very sensitive to the shape of the EEDF.

The steady state $\mathrm{H}^{-}$profile is determined by several factors, the most important of which is the asymmetry of the electric potential (Fig. 3), since negative ions will flow towards the bottom of the plasma potential energy well. In order to understand the relative importance of transport compared to the location of the creation zone, we performed several simulations with an artificially symmetrized negative ion production. In these simulations, newly created negative ions at position $x$, are instead created randomly at positions either $x$ or $d-x$. The plots (Fig. 8), which refer to 3 different waveforms including the saw-tooth case discussed in the next section, show that the profile shape and asymmetry is little affected by this symmetrisation, but the negative ion number density is significantly lower; details of the profile shapes artificially normalized to the same density also display small but non negligible differences. This comparison demonstrates that while the position of the maximum in the $\mathrm{H}^{-}$number density profile is determined by the potential well, details of the ion cloud shape are affected by the production rate profile. This effect also demonstrates that the $\mathrm{H}^{-}$transport is a critical issue, since ions produced further away from the gathering location have a higher chance of being destroyed by reactive channels such as detachment. In [22] asymmetric negative ions density profiles in a CCP driven by TVWs in $\mathrm{CF}_{4}$ were observed. In particular, for a 'Peaks' waveform, they found that the discharge is split into an electropositive half and a strongly electronegative half, due to a complicated mechanisms of field reversals and a potential well near the grounded electrode, that is not observed in the present results. Moreover, in [44], an 
effect of adjusting the phase between two consecutive harmonics on the ion density profile was observed at low pressures (22.5 mTorr) in Ar. A similar effect to the one found in the present results was found, but with a value of the phase shift halved, due to the different waveform used therein.
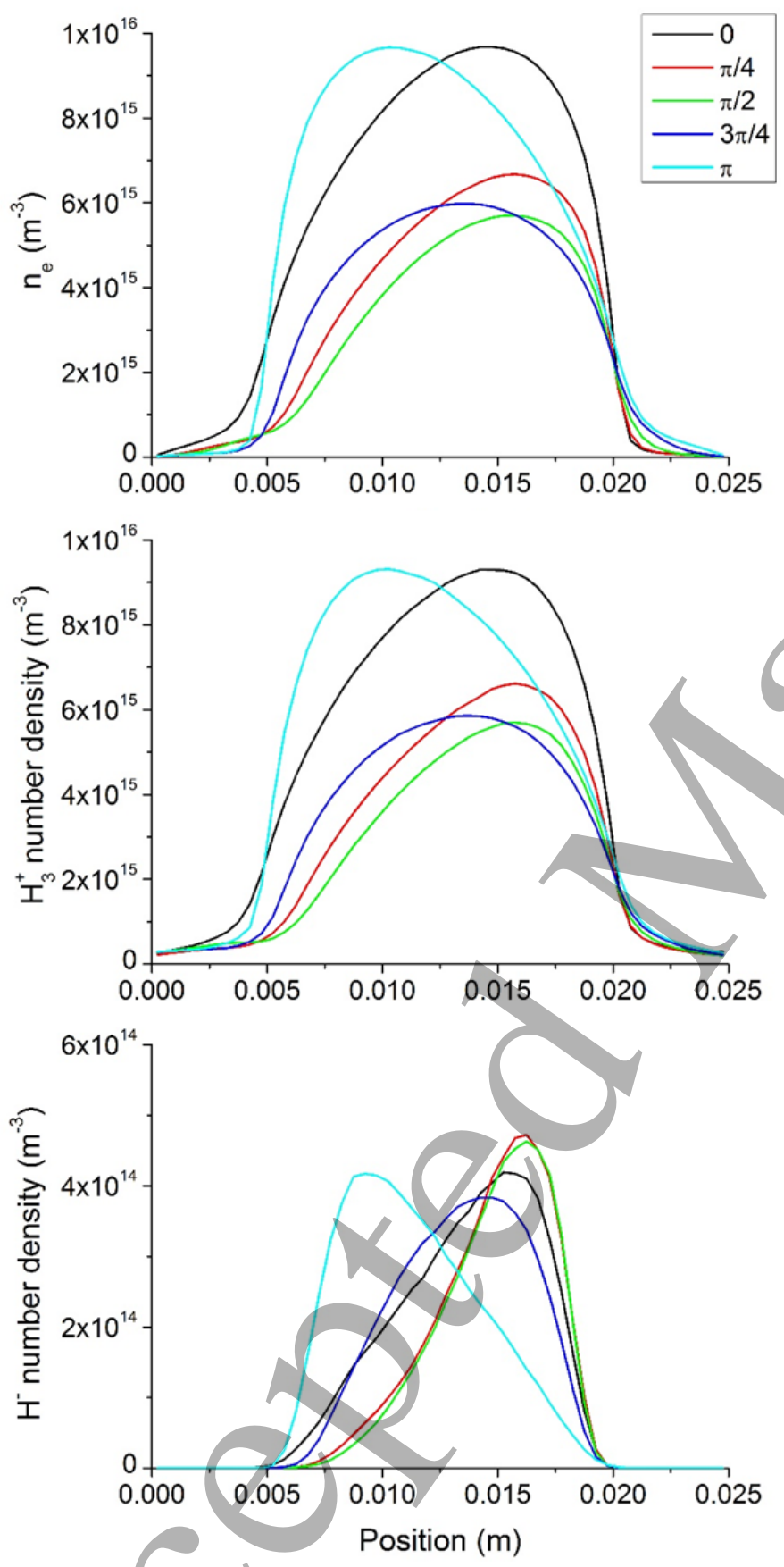

Fig. 2 Time-averaged electron, $\mathrm{H}_{3}{ }^{+}$and $\mathrm{H}^{-}$number densities as a function of position across the discharge gap for different values of the phase shift in a peaks-type voltage waveform. 


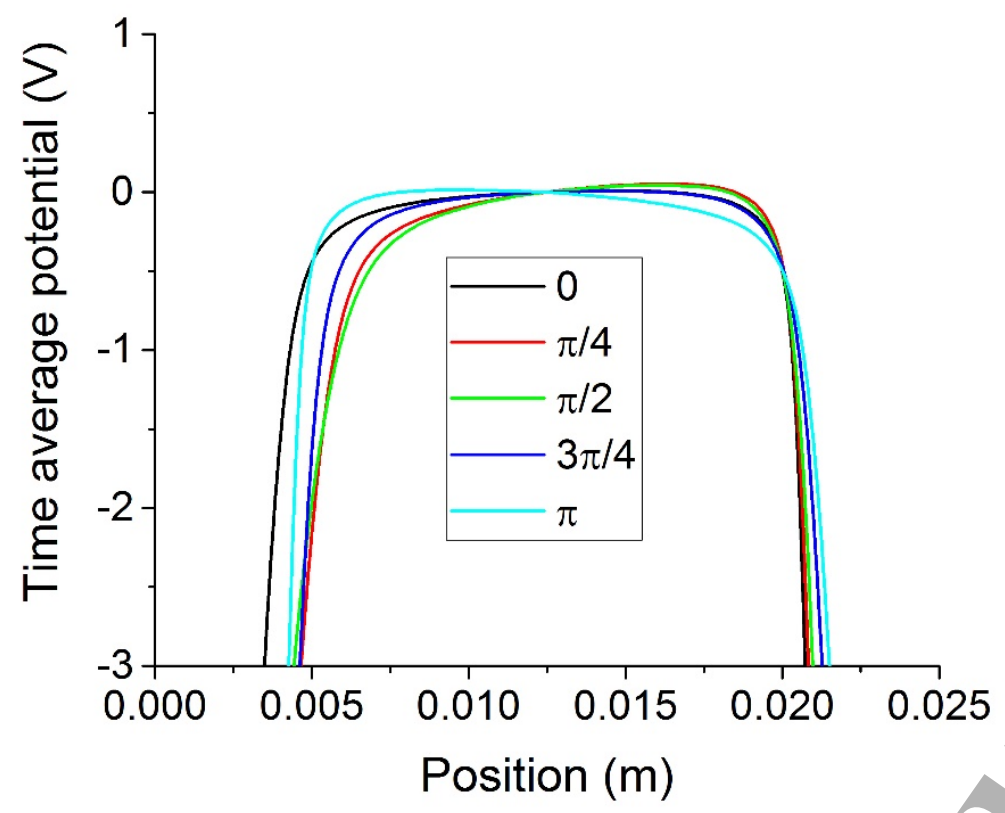

Fig. 3 Time average plasma potential as a function of position across the discharge gap for different values of the phase shift in a peaks-type voltage waveform.For representation purposes, the zero has been set at half the inter-electrode gap and the y-axis scale has been limited to a short range.

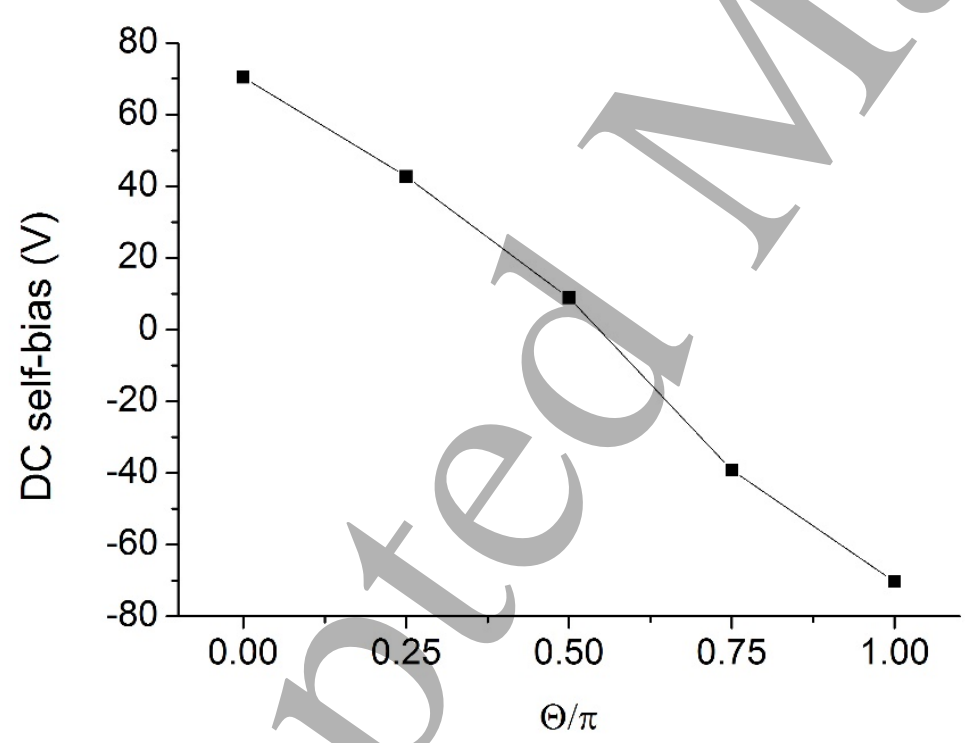

Fig. 4 DC self-bias as a function of the phase shift in a peaks-type voltage waveform. 


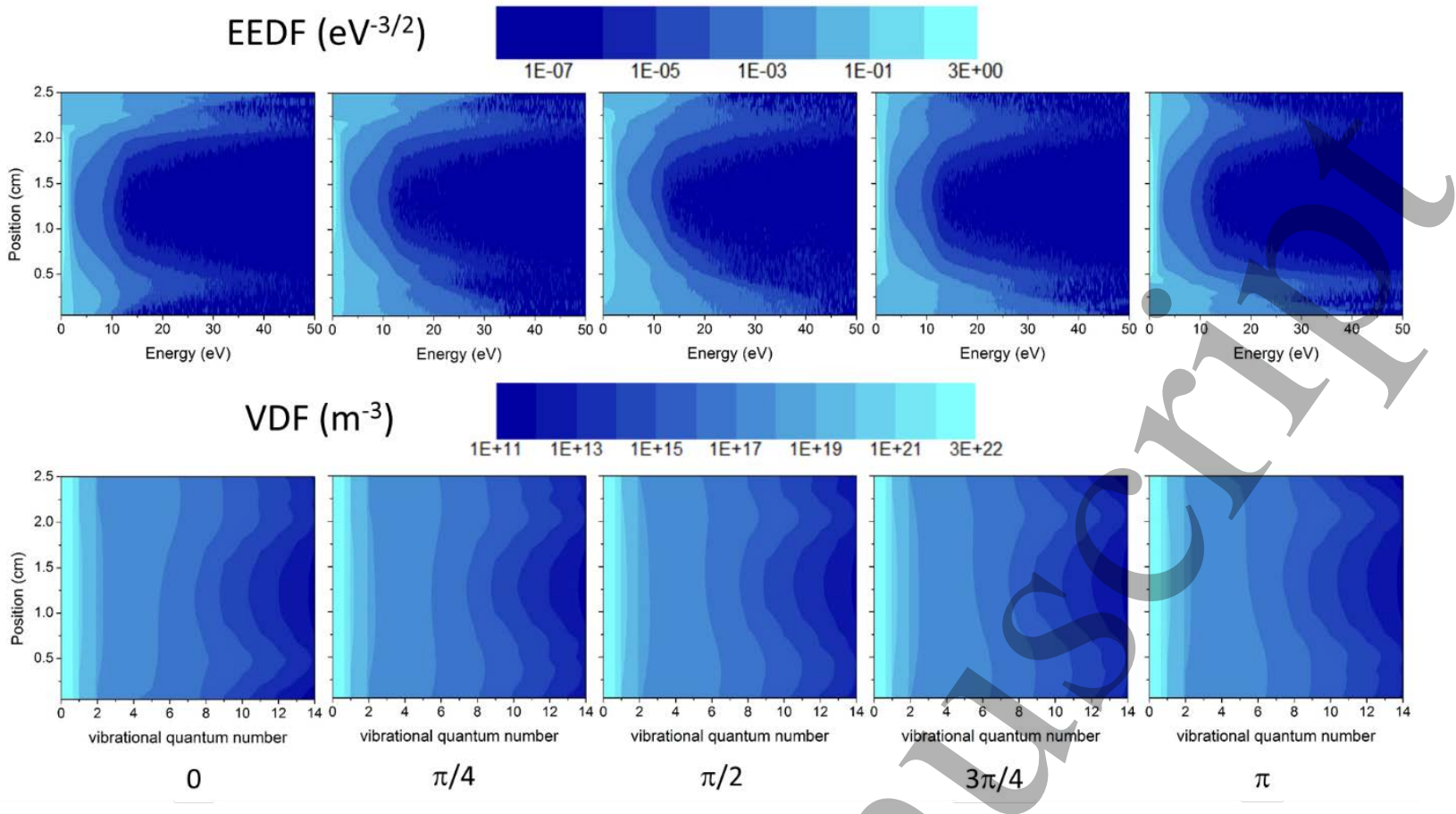

Fig. 5 Time-averaged electron energy distribution function (top row) and vibrational distribution function (bottom row) as a function of position across the discharge gap for different values of the phase shift in a peaks-type voltage waveform. 


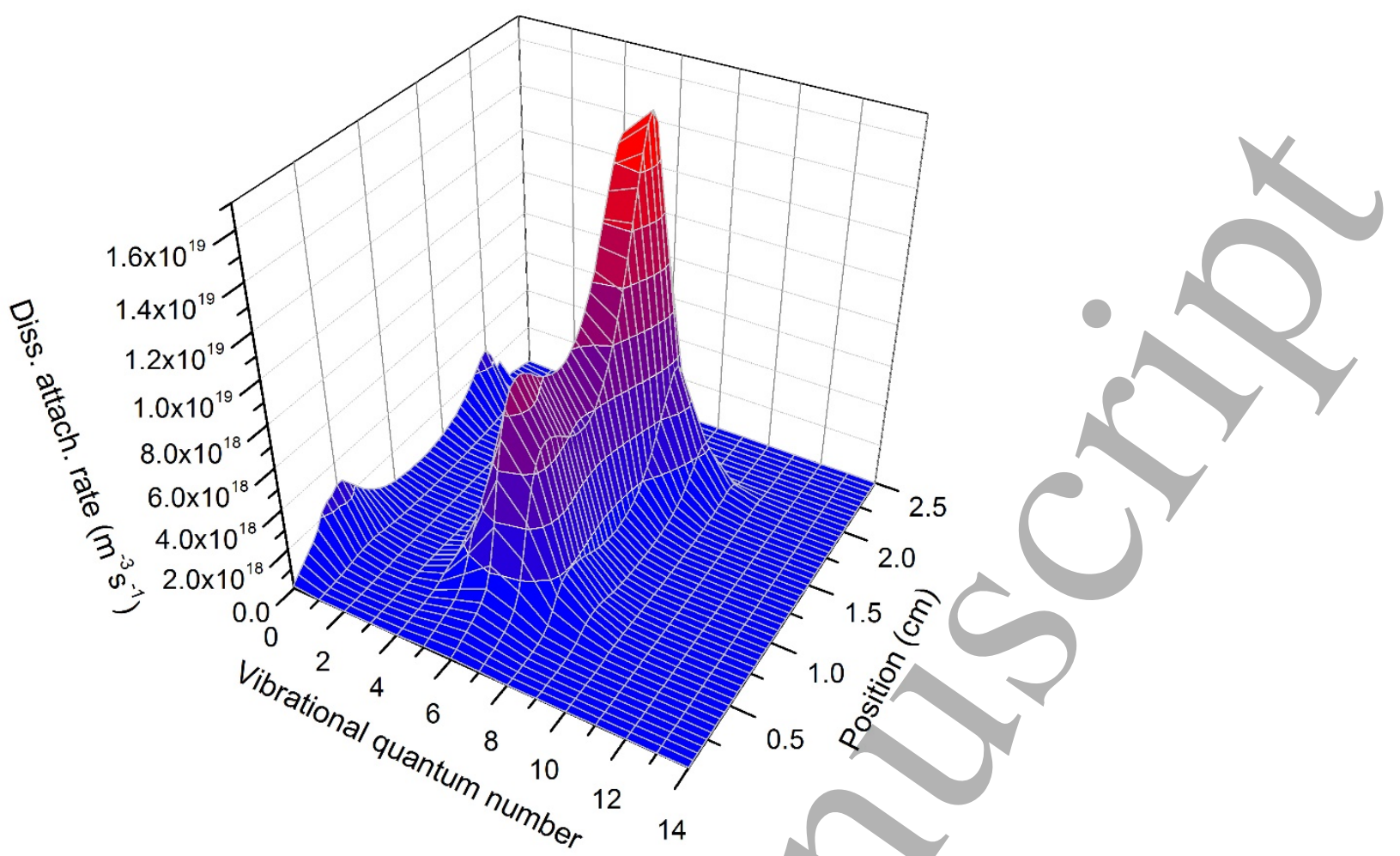

Fig. 6 Dissociative attachment rate as a function of the position across the discharge gap and the quantum number of the vibrationally excited state of the $\mathrm{H}_{2}$ molecule, for a phase shift $\Theta=0$ in a peaks-type voltage waveform.

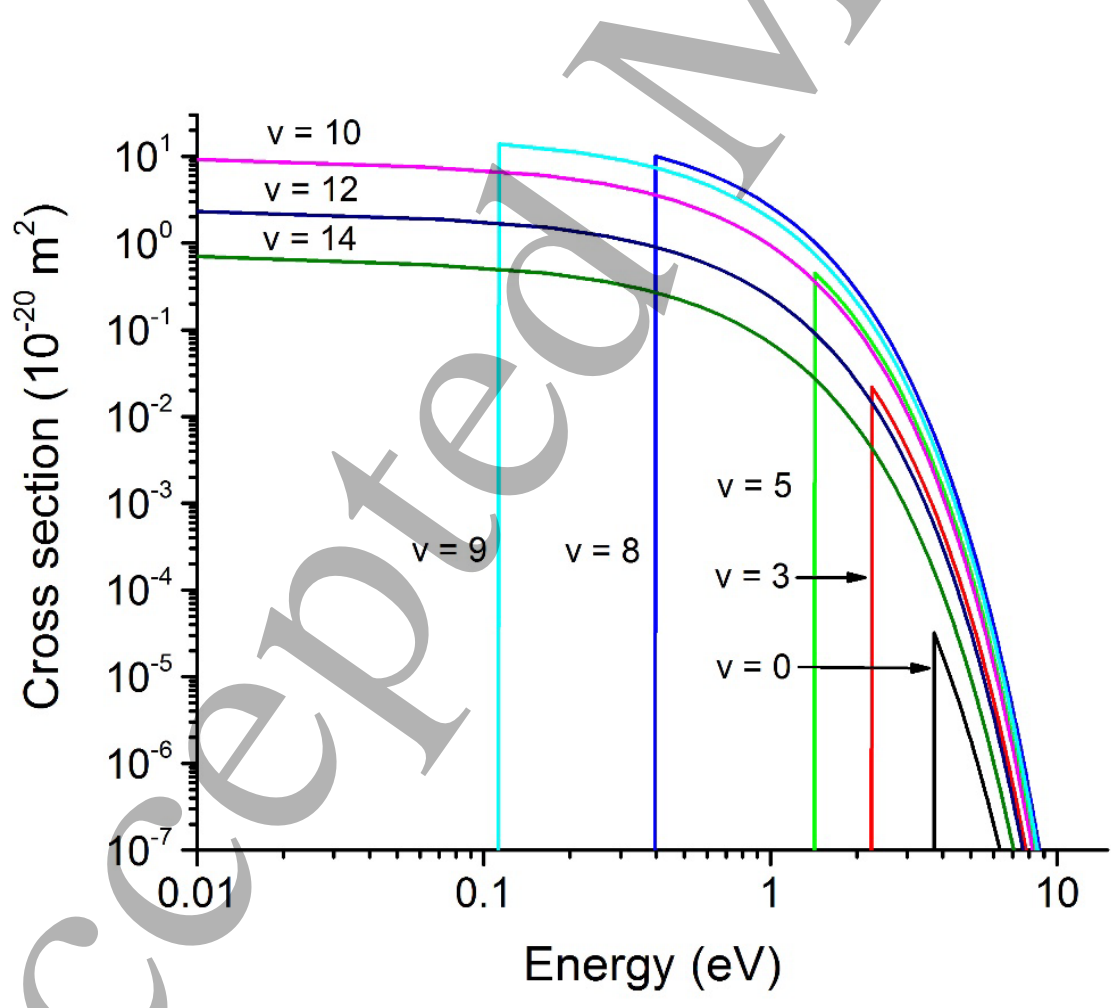

Fig. 7 Cross sections of electron dissociative attachment of $\mathrm{H}_{2}$ molecules for selected vibrational states of the target molecule, based on data of [37]. 

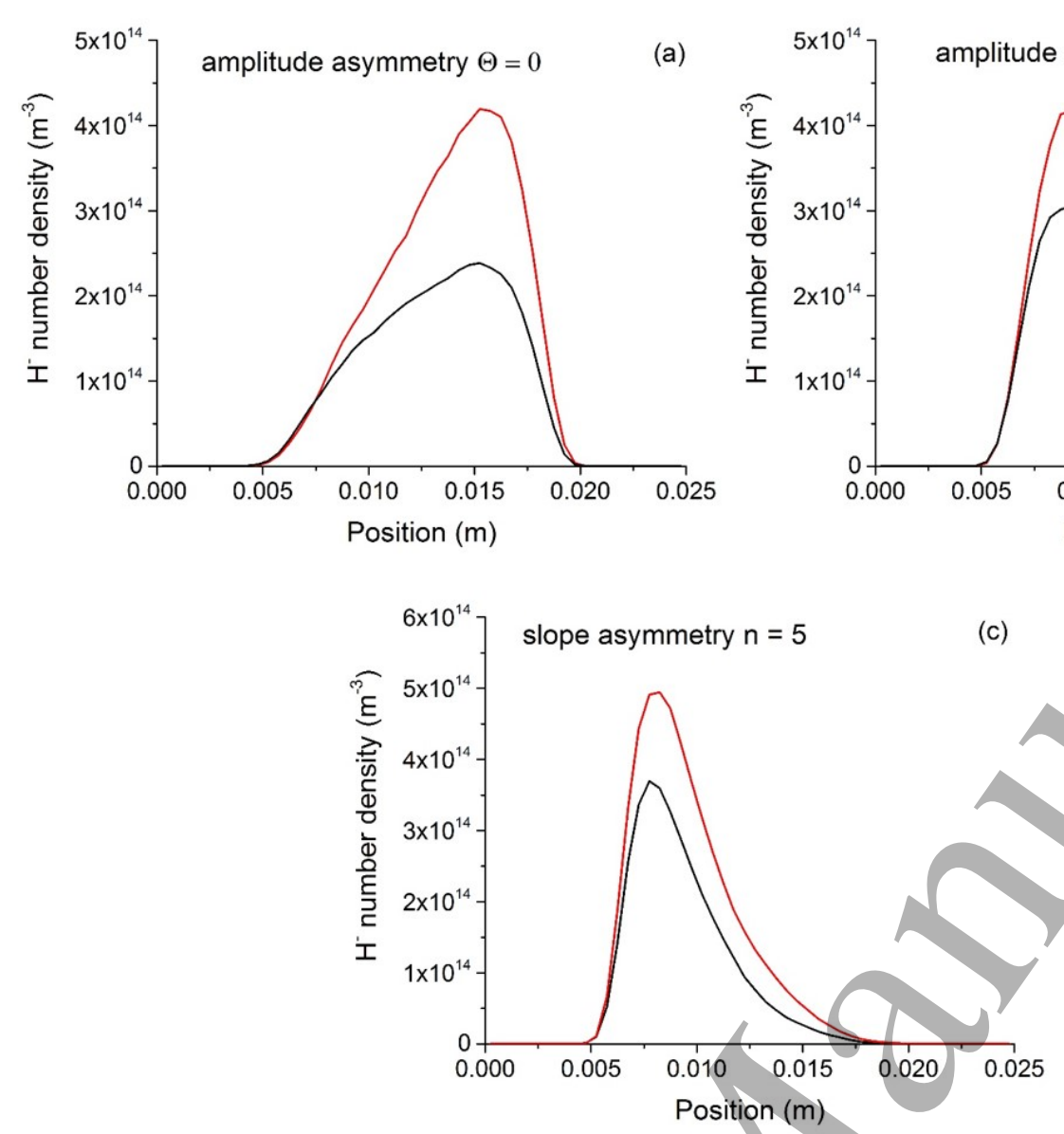

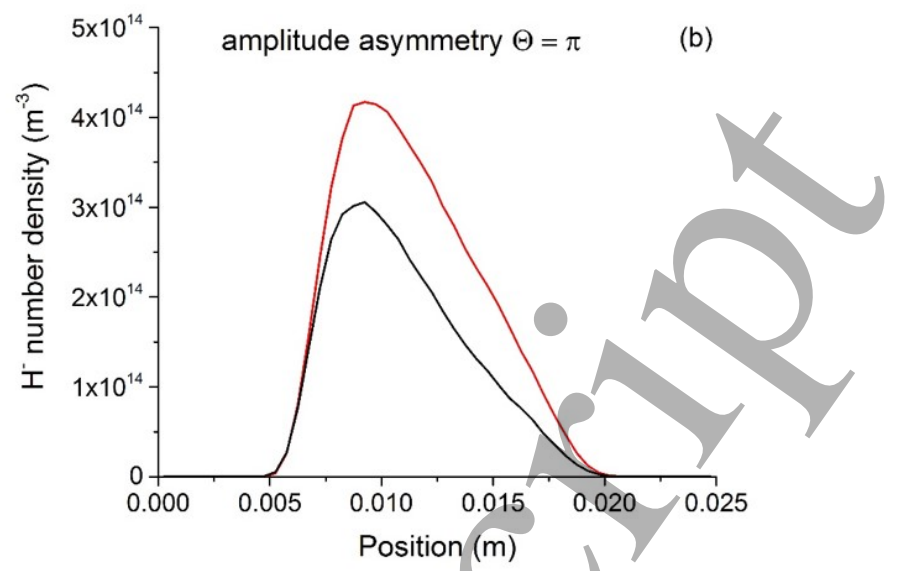

(c)

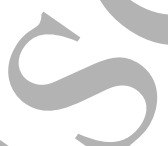

\section{Slope asymmetry}

Fig. 8 Time-average $\mathrm{H}^{-}$number density as a function of position across the discharge gap without (red line) and with (black line) an artificially symmetrized negative ion production, for 3 different waveforms: (a) amplitude asymmetry with $\Theta=0$, (b) amplitude asymmetry with $\Theta=\pi$, (c) slope asymmetry with $\mathrm{n}=5$.

In this section saw-tooth waveforms, as in Eq. (6), are used, and the number of harmonics composing the waveform $n$ is varied from 1 to 5 to control the slope asymmetry of the waveform, as shown in Fig. 9. The peak-to-peak voltage $V_{P P}$ is kept constant at $350 \mathrm{~V}$.

$$
V_{A C}(t)=-V_{0} \sum_{k=1}^{n} \frac{1}{k} \sin (k \omega t)
$$

The harmonics' amplitudes are chosen to maximize the asymmetry in the waveforms, that have slope asymmetry, increasing with $n$, but no amplitude asymmetry. The $1 / k$ prefactors 
maximize the slope asymmetry for a given $n$. Saw-tooth waveforms induce fast expansion and slow contraction of the sheath close to one electrode, and slow expansion and fast contraction in the sheath in front of the opposite electrode [45].

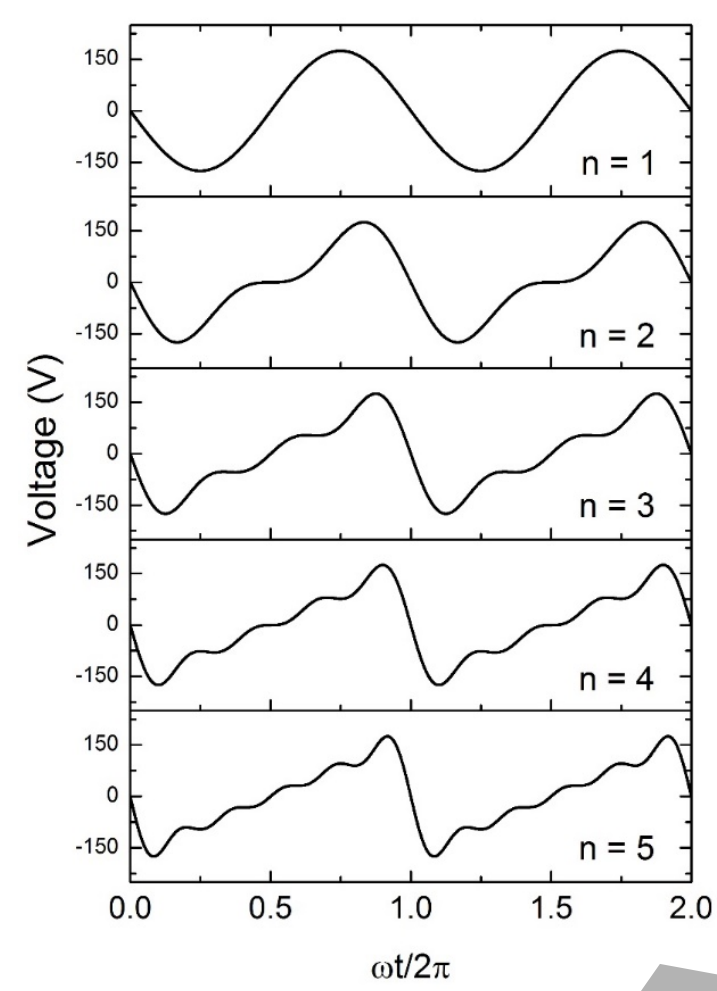

Fig. 9 Voltage waveforms (saw-tooth) for the slope asymmetry case: the number of harmonics $n$ in Eq. (6) is varied, whereas the peak-to-peak voltage is kept constant at $350 \mathrm{~V}$.

As shown in Fig. 10, the plasma density increases with the number of harmonics, and, given the electrical asymmetry of the discharge, the maximum in the electron density spatial profile shifts towards the powered electrode. The same is valid for the negative ions that follow the shift in the maximum of the time average plasma potential (Fig. 11). As in the previous case, $\mathrm{H}^{+}$ions (not shown) have a similar trend to the one of $\mathrm{H}_{3}{ }^{+}$, but with a number density about an order of magnitude smaller. $\mathrm{H}_{2}{ }^{+}$ions (also not shown) have a double maximum structure, each maximum close to the sheath, the one on the left with an height twice as much as the height of the right for $n>1$. Both maxima increase in height and shift towards the electrode with the number of harmonics. Similarly to the case at the lower frequency [18], strong excitation of the $\mathrm{H}(\mathrm{n}=3)$ is observed during the fast sheath expansion as well as during the fast sheath contraction at the opposite electrode (not shown). The latter is due to a field reversal, 
needed to accelerate electrons from the plasma bulk to the electrode to balance the ion flux. Therefore, the discharge is characterized by a weak spatial asymmetry. From the EEDF and the VDF plots (Fig. 12), the mechanism that favours negative ion formation for the saw-tooth waveform can be inferred: it is based on a combination of the increased vibrational excitation, due to the higher plasma density, and the asymmetry of the discharge, that gives rise to lower energy electrons close to the powered electrode $(x=0)$. Low energy electrons produce negative ions through dissociative attachment of vibrationally excited states. A contribution to the spatial profile of negative ions is also given by the ion transport in the asymmetric electric field, as discussed in the previous section (see Fig. 8).

In Fig. 13 the DC self-bias is shown: As in ref. [18], the discharge remains nearly symmetric also in this higher frequency case, therefore the value of the self-bias is low.

The slope asymmetry case also differs from the amplitude asymmetry case, due to the different spatio-temporal electron dynamics, in featuring an almost symmetrical VDF, except for a few lower levels. Fig. 14 shows that the spatial variation of the production rate of negative ions is actually much less marked, although an opposite asymmetry is seen in the contributions from low vibrational levels as opposed to higher levels, due to opposing trends in the plasma density and the EEDF asymmetry.

The strong displacement of the peak of the $\mathrm{H}^{-}$density profile away from the plasma centre and the possibility of controlling this displacement by changing the number of harmonics may be useful for applications which require control of the position of a cloud of negative ions. The spatially asymmetric density profiles in the case of saw-tooth up waveforms can be mirrored in space by using a saw-tooth down waveform, that is switching the sign from minus to plus in Eq. (6).

In this context, the frequency of the applied voltage plays a major role. Fig 15 shows the results when the model is run at the lower frequency of $5 \mathrm{MHz}$ (as in ref. [18]). In this case changing the phase shift has a much smaller effect on the position of the maximum in the negative ions density. Furthermore, increasing the number of harmonics increases the number density but has only a minor effect on the position of the maximum. This difference is due to the fact that, in the low frequency case, the position of the bottom of the potential well is hardly affected by the phase shift or the number of harmonics in the waveforms, contrarily to what happens in the high frequency case. 

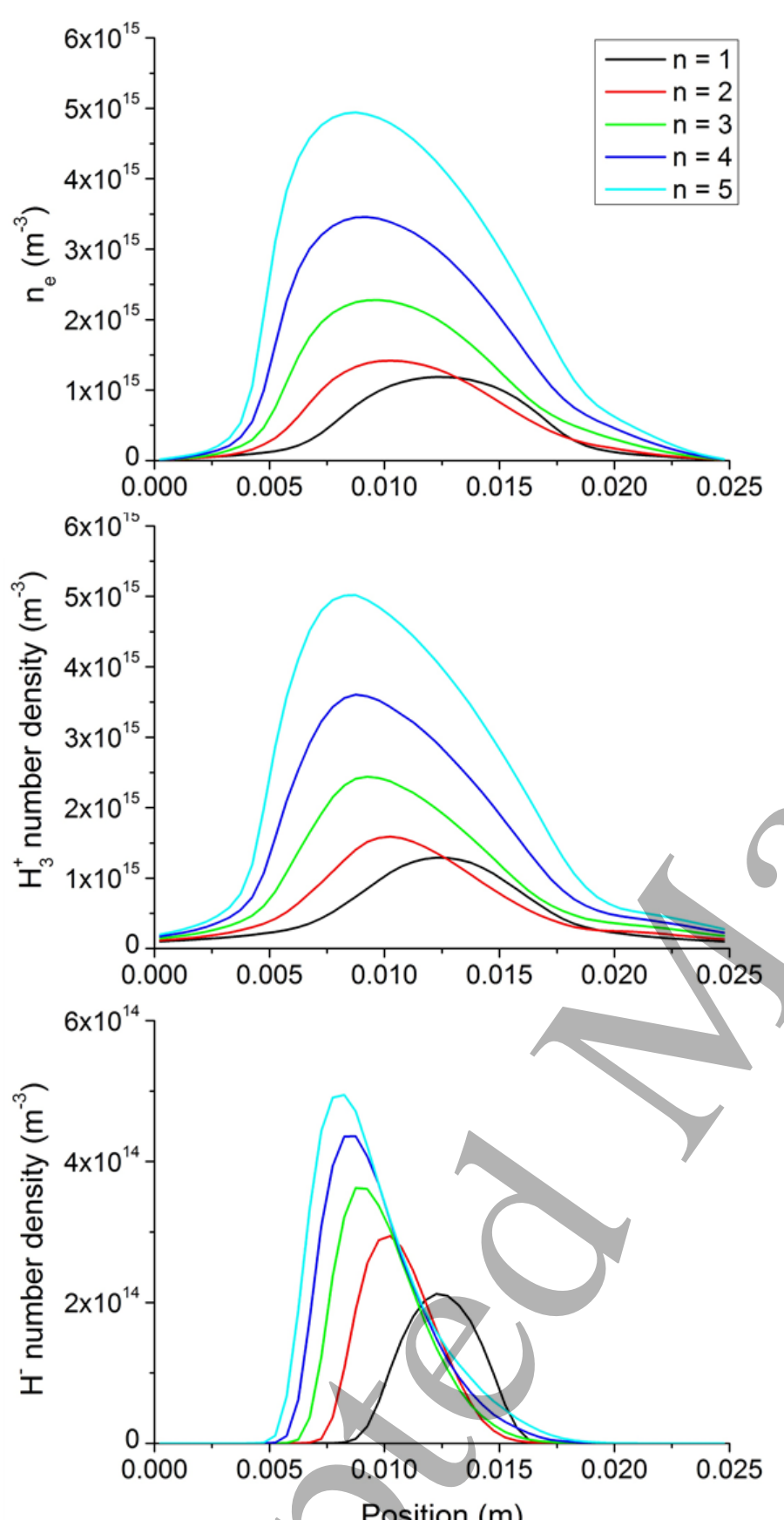

Position (m)

Fig. 10 Time-averaged electron, $\mathrm{H}_{3}{ }^{+}$and $\mathrm{H}^{-}$number densities as a function of position across the discharge gap with saw-tooth waveforms with different numbers of harmonics in the voltage waveform. 


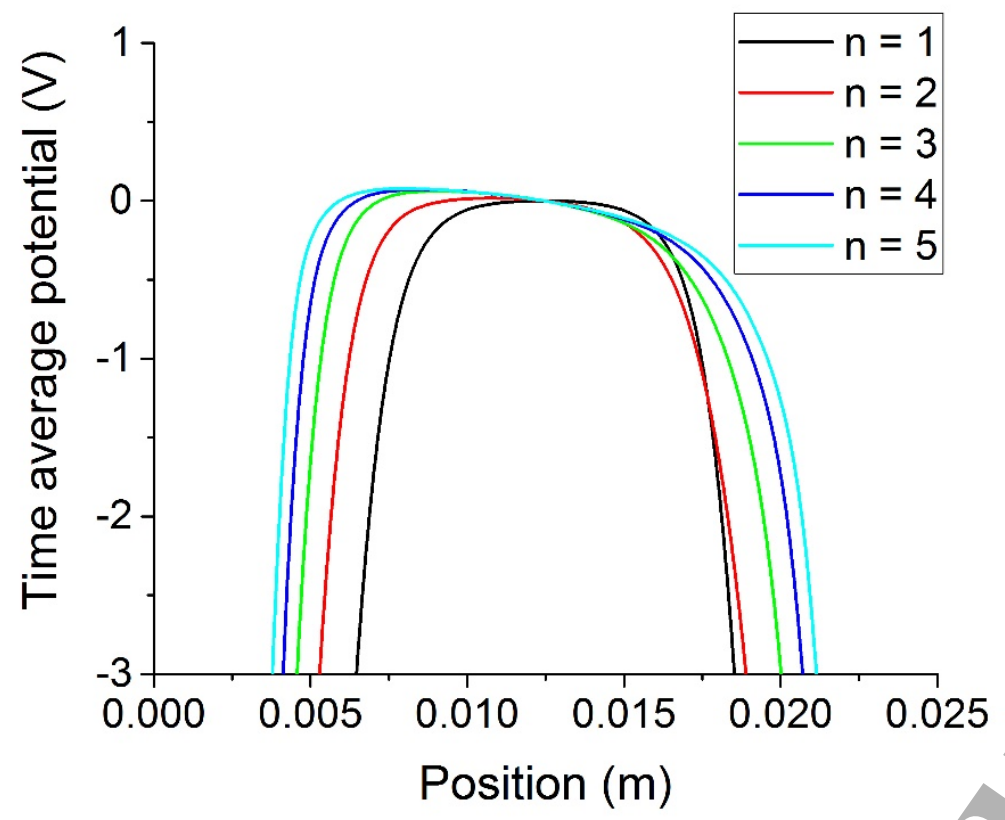

Fig. 11 Time average plasma potential as a function of position across the discharge gap for different values of number of harmonics in a saw-tooth voltage waveform. For representation purposes, the zero has been set at half the inter-electrode gap and the y-axis scale has been limited to a short range.

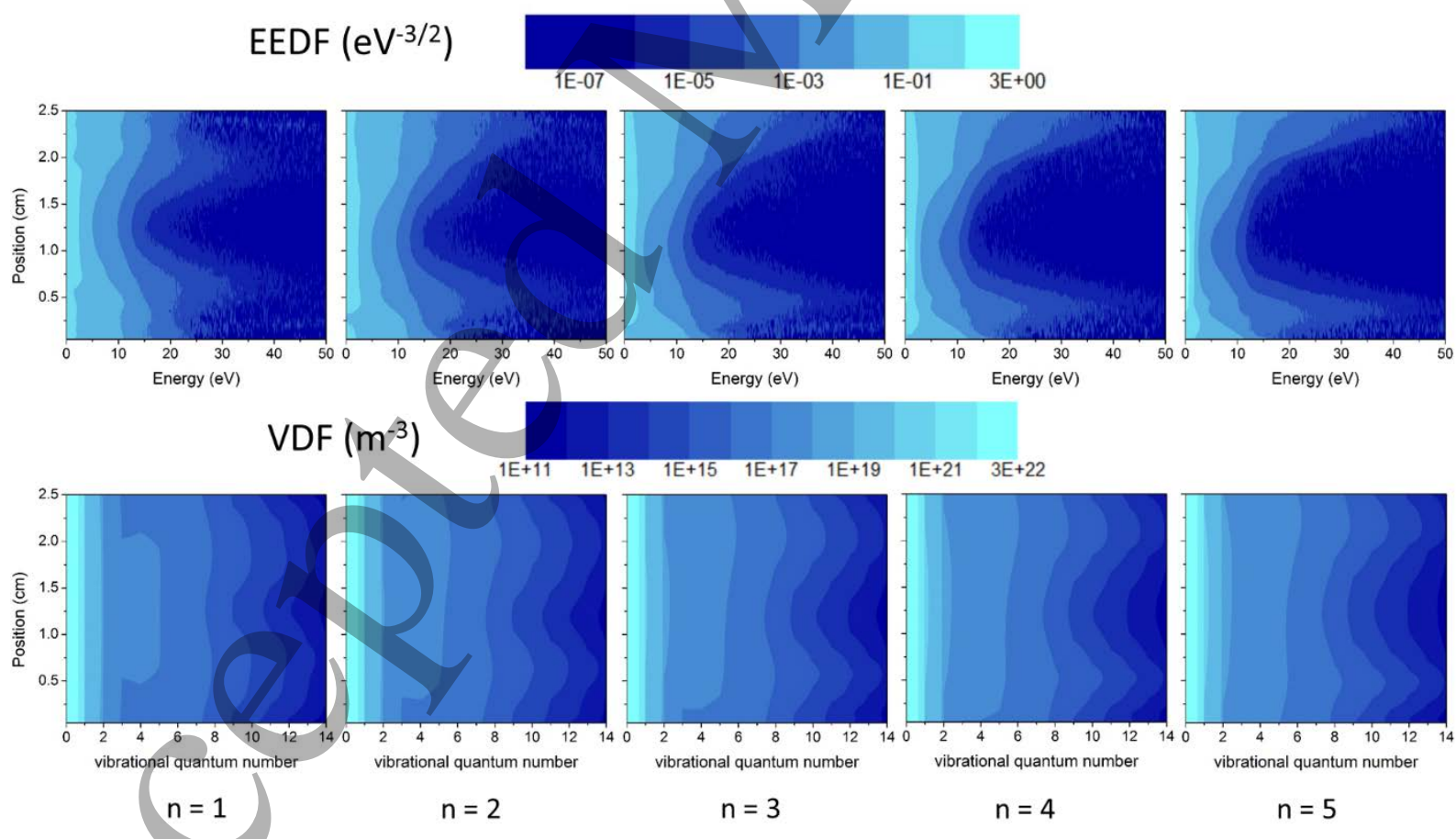

Fig. 12 Time-average electron energy distribution function (top row) and vibrational distribution function (bottom row) as a function of position across the discharge gap for different values of the number of harmonics in a saw-tooth voltage waveform. 


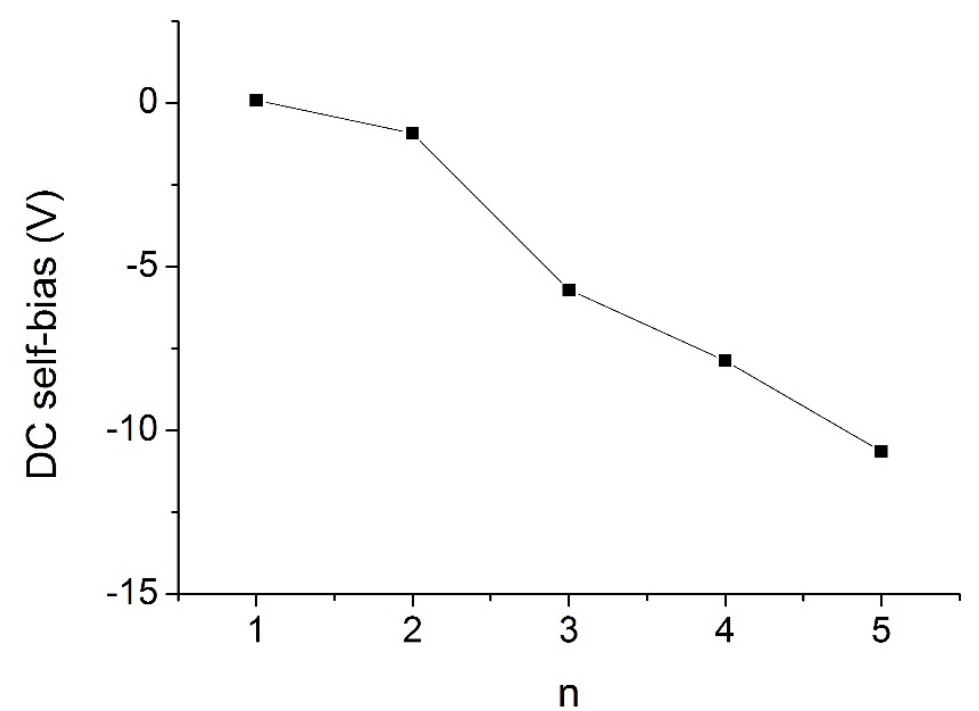

Fig. 13 DC self-bias as a function of the number of harmonics in a saw-tooth voltage waveform. 


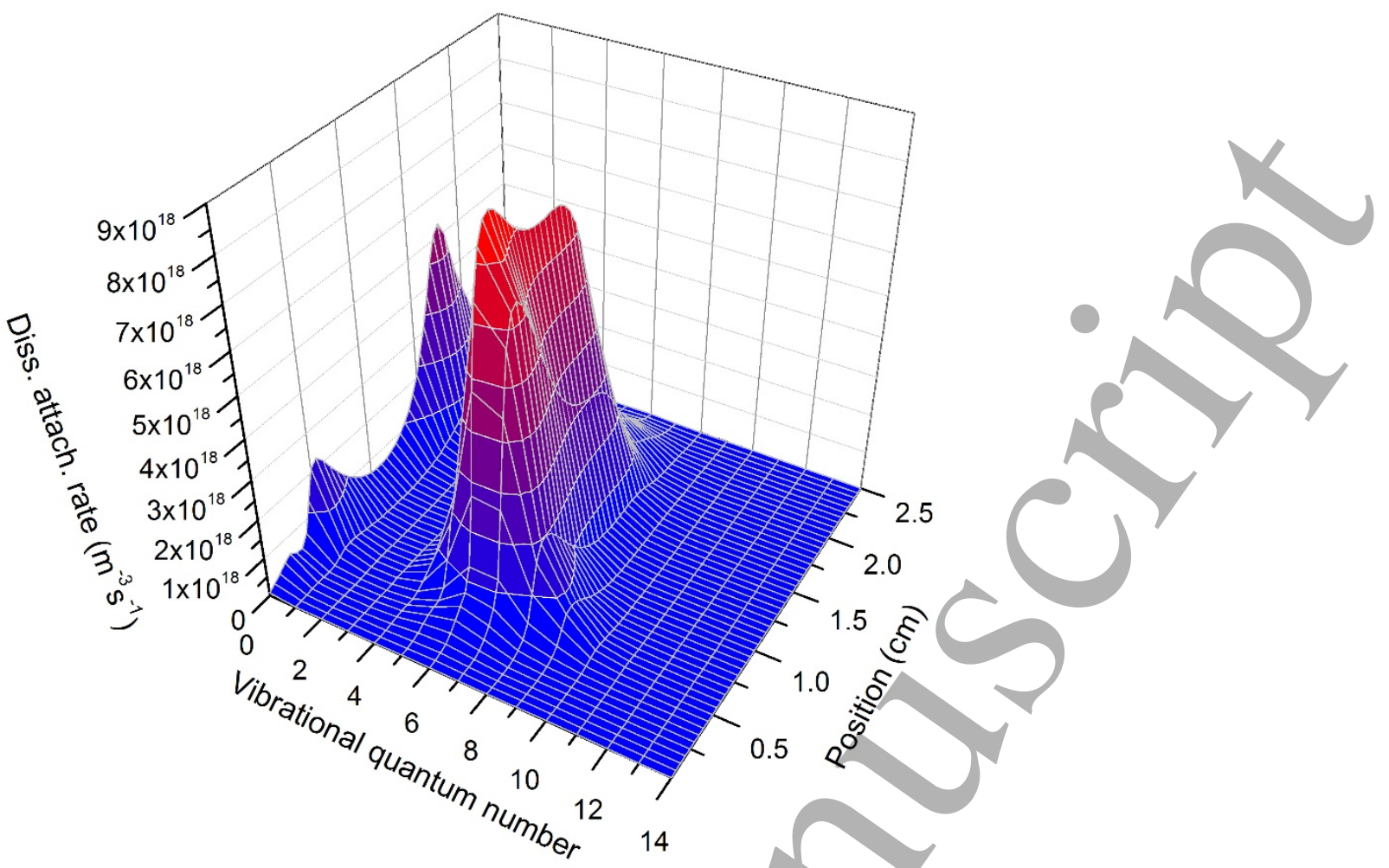

Fig. 14 Dissociative attachment rate as a function of the position across the discharge gap and the quantum number of the vibrationally excited state of the $\mathrm{H}_{2}$ molecule, for $n=5$ harmonics in the voltage waveform.

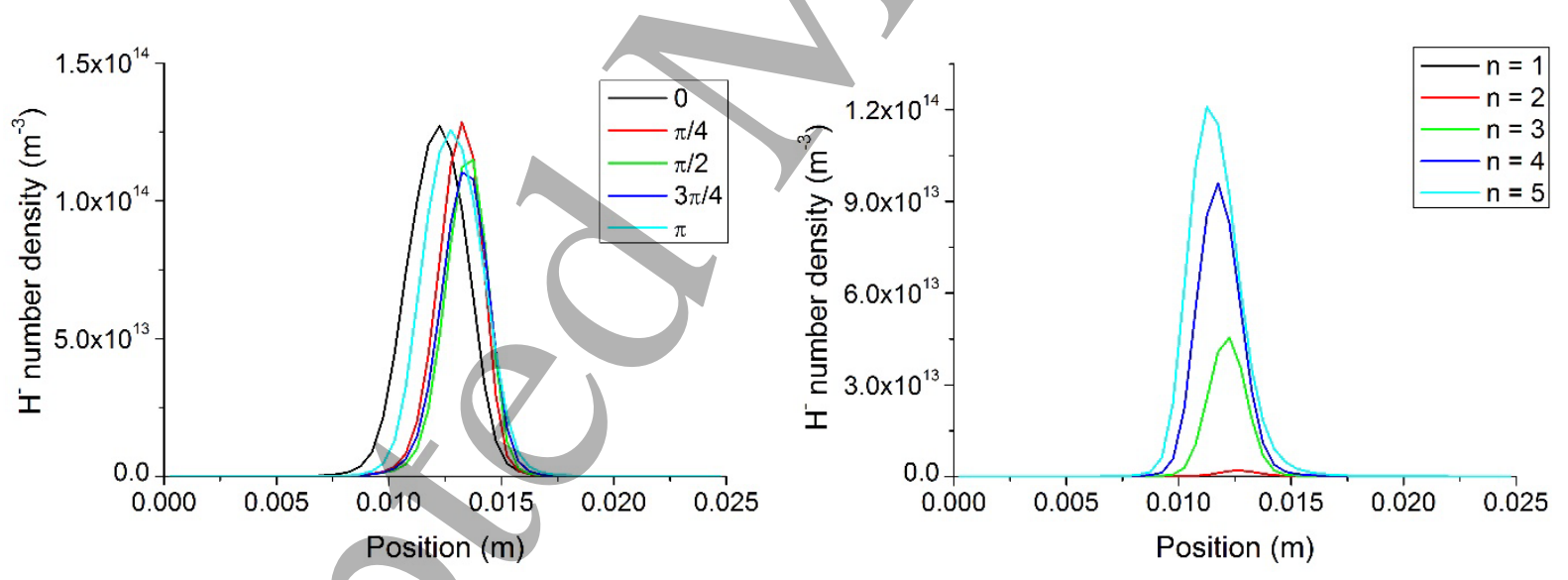

Fig. 15 Time-average $\mathrm{H}^{-}$number density as a function of position across the discharge gap for different values of phase shift (left) and number of harmonics (right) in the voltage waveform, for a frequency of $5 \mathrm{MHz}$.

\section{Conclusions}

In this paper a computational study is performed of the effect of TVWs comprised of a sum of harmonics on the vibrational kinetics and negative ion production of CCPs in hydrogen, by 
means of a hybrid kinetic/fluid model. Two series of cases were analysed: for the valleys-topeak waveforms (amplitude asymmetry) the phase shift was changed while keeping the number of harmonics constant, whereas for the saw-tooth waveforms (slope asymmetry) the number of harmonics was increased from 1 to 5 . In contrast to our previous results at $5 \mathrm{MHz}$, when the frequency of the applied RF voltage is increased to $13.56 \mathrm{MHz}$ for the saw-tooth case a strong dependence of the negative ion number density on the number of harmonics is observed, with an asymmetric profile caused by a combination of the increased vibrational excitation due to the higher plasma density, and the asymmetry of the discharge, that causes more low energy electrons close to the powered electrode and also affects the negative ion transport in the electric field. For the amplitude asymmetry waveforms, the maximum in the negative ion number density profile can be changed with the phase shift in the applied voltage. Vibrational kinetics plays an important role in producing these strongly asymmetric negative ion density profiles. This form of control over the peak density and spatial location of the negative ions inside a discharge plasma may find interesting applications in view of the reactivity of negative hydrogen ions.

\section{Acknowledgements}

P. D. is grateful to Dr. E. Westerhof and Dr. P. Klaver from DIFFER for helping her to adapting the code to run on the computational servers at DIFFER. 


\section{References}

[1] B. Kalache, T. Novikova, A. Fontcuberta i Morral, P. Roca i Cabarrocas, W. Morscheidt, K. Hassouni, "Investigation of coupling between chemistry and discharge dynamics in radio frequency hydrogen plasmas in the Torr regime”, J. Phys. D: Appl. Phys. 37, 1765 (2004).

[2] R.S. Hemsworth, A. Tanga and V. Antoni, "Status of the ITER neutral beam injection system”, Rev. Sci. Instrum. 79, 02C109 (2008).

[3] U. Fantz, H. Falter, P. Franzen, D. Wünderlich, M. Berger, A. Lorenz, W. Kraus, P. McNeely, R. Riedl and E. Speth, "Spectroscopy-a powerful diagnostic tool in source development”, Nucl. Fusion 46, S297-306 (2006).

[4] M. Capitelli, M. Cacciatore, R. Celiberto, O. De Pascale, P. Diomede, F. Esposito, A. Gicquel, C. Gorse, K. Hassouni, A. Laricchiuta, S. Longo, D. Pagano, M. Rutigliano "Vibrational Kinetics, Electron Dynamics and Elementary Processes in $\mathrm{H}_{2}$ and $\mathrm{D}_{2}$ Plasmas for Negative Ion Production: Modelling Aspects”, Nucl. Fusion, 46, S260 (2006).

[5] M. Bacal and M. Wada, "Negative hydrogen ion productíon mechanisms”, Appl. Phys. Rev., 2, 021305 (2015).

[6] A. Hatayama, T. Sakurabayashi, Y. Ishi, K. Makino, M. Ogasawara, and M. Bacal, "Development of multidimensional Monte Carlo simulation code for $\mathrm{H}^{-}$ion and neutral transport in $\mathrm{H}^{-}$ion sources”, Rev. Sci. Instrum., 73, 910, (2002).

[7] F. Taccogna, R. Schneider, S. Longo and M. Capitelli, "Modeling of a negative ion source. I. Gas kinetics and dynamics in the expansion region”, Phys. Plasmas 14, 073503 (2007).

[8] F. Gaboriau and J. P. Boeuf, "Chemical kinetics of low pressure high density hydrogen plasmas: application to negative ion sources for ITER”, Plasma Sources Sci. Technol. 23, 065032 (2014).

[9] P. Diomede, S. Longo, M. Capitelli, “Vibrational excitation and negative ion production in radio frequency parallel plate $\mathrm{H}_{2}$ plasmas”, Eur. Phys. J. D, 33, 243 (2005).

[10] P. Diomede, K. Hassouni, S. Longo and M. Capitelli, "Self-consistent modeling of the effect of wall-neutral reactions on parallel plate radio frequency discharge plasma in pure hydrogen”, IEEE Trans. Plasma Science, 35, 1241 (2007). 
[11] T. Lafleur, "Tailored-waveform excitation of capacitively coupled plasmas and the electrical asymmetry effect”, Plasma Sources Sci. Technol. 25, 013001 (2016).

[12] B. G. Heil, U. Czarnetzki, R. P. Brinkmann and T. Mussenbrock, “On the possibility of making a geometrically symmetric RF-CCP discharge electrically asymmetric”, J. Phys. D: Appl. Phys., 41, 165202 (2008).

[13] P. Diomede, A. Michau, M. Redolfi, W. Morscheidt, K. Hassouni, S. Longo and M. Capitelli, "Fluid and kinetic models of the low temperature $\mathrm{H}_{2}$ plasma produced by a radiofrequency reactor”, Phys. Plasmas, 15, 103505 (2008).

[14] P. Diomede, M. Capitelli, S. Longo "Effect of discharge voltage on capacitively coupled, parallel plate rf hydrogen plasmas”, Plasma Sources Sci. Technol., 14, 459(2005).

[15] P. Diomede, D. J. Economou, T. Lafleur, J.-P. Booth, and S. Longo, "Radio-frequency capacitively coupled plasmas in hydrogen excited by tailored voltage waveforms: comparison of simulations with experiments”, Plasma Sources Sci. Technol., 23, 065049 (2014).

[16] P. Diomede, S. Longo, D. J. Economou, and M. Capitellí, "Hybrid simulation of a dcenhanced radio-frequency capacitive discharge in hydrogen”, J. Phys. D: Appl. Phys., 45, 175204 (2012).

[17] B. Bruneau, T. Lafleur, T. Gans, D. O’Connell, A. Greb, I. Korolov, A. Derzsi, Z. Donkó, S. Brandt, E. Schüngel, J Schulze, P. Diomede, D. J. Economou, S. Longo, E. Johnson, and J.-P. Booth, "Effect of gas properties on the dynamics of the electrical slope asymmetry effect in capacitive plasmas: comparison of Ar, $\mathrm{H}_{2}$ and $\mathrm{CF}_{4}$ ”, Plasma Sources Sci. Technol., 25, 01LT02 (2016).

[18] B. Bruneau, P. Diomede, D. J. Economou, S. Longo, T. Gans, D. O’Connell, A. Greb, E. Johnson, J.-P. Booth, “Capacitively coupled hydrogen plasmas sustained by tailored voltage waveforms: excitation dynamics and ion flux asymmetry”, Plasma Sources Sci. Technol., 25, 045019 (2016).

[19] S. Mohr, E. Schüngel, J. Schulze, and U. Czarnetzki, "Ion Distribution Functions in Electrically Asymmetric Capacitively Coupled Radio-Frequency Discharges in Hydrogen”, IEEE Trans. on Plasma Sci., 42, 2376 (2014).

[20] S. Mohr, E. Schüngel, J. Schulze, and U. Czarnetzki, "Field reversals in electrically asymmetric capacitively coupled radio-frequency discharges in hydrogen”, J. Phys. D: Appl.

Phys., 46, 435201 (2013). 
[21] E. Schüngel, S. Mohr, J. Schulze, U. Czarnetzki, and M. J. Kushner, "Ion distribution functions at the electrodes of capacitively coupled high-pressure hydrogen discharges”, Plasma Sources Sci. Technol., 23, 015001 (2014).

[22] S. Brandt, B. Berger, E. Schüngel, I. Korolov, A. Derzsi, B. Bruneau, E. Johnson, T. Lafleur, D. O’Connell, M. Koepke, T. Gans, J.-P. Booth, Z. Donkó and J. Schulze, 'Electron power absorption dynamics in capacitive radio frequency discharges driven by tailored voltage waveforms in CF4”, Plasma Sources Sci. Technol., 25, 045015 (2016).

[23] E. Schüngel, I. Korolov, B. Bruneau, A. Derzsi, E. Johnson, D. O’Connell, T. Gans, J.-P. Booth, Z. Donkó and J. Schulze, “Tailored voltage waveform capacitively coupled plasmas in electronegative gases: frequency dependence of asymmetry effects", J. Phys. D: Appl. Phys., 49, 265203 (2016).

[24] A. Derzsi, B. Bruneau, A. R. Gibson, E. Johnson, D. O’Connell, T. Gans, J.-P. Booth and Z. Donkó, "Power coupling mode transitions induced by tailored voltage waveforms in capacitive oxygen discharges”, Plasma Sources Sci. Technol., 26, 034002 (2017).

[25] C. K. Birdsall and A. B. Langdon, Plasma Physics via Computer Simulation. McGrawHill, New York, 1985.

[26] R. W. Hockney and J. W. Eastwood, Computer Simulation Using Particles. CRC Press, 1988.

[27] S. Longo, "Monte Carlo simulation of charged species kinetics in weakly ionized gases”, Plasma Sources Sci. Technol., 15, S181 (2006).

[28] P. Diomede and S. Longo, "Velocity Distribution of $\mathrm{H}^{-}$Ions in Low Temperature Hydrogen Plasma”, IEEE Trans. Plasma Sci., 36, 1600 (2008).

[29] http://jila.colorado.edu/ avp/collision data/electronneutral/ELECTRON.TXT

[30] J. Loureiro and C. M. Ferreira, "Electron and vibrational kinetics in the hydrogen positive column” J. Phys. D: Appl. Phys., 22, 1680 (1989).

[31] C. Gorse, M. Capitelli, M. Bacal, J. Bretagne and A. Laganà, "Progress in the nonequilibrium vibrational kinetics of hydrogen in magnetic multicusp $\mathrm{H}^{-}$ion sources”, Chem. Phys., 117, 177 (1987). 
[32] R. Celiberto, R. K. Janev, A. Laricchiuta, M. Capitelli, J. M. Wadehra and D. E. Atems, "Cross section data for electron-impact inelastic processes of vibrationally excited molecules of hydrogen and its isotopes”, At. Data Nucl. Data Tables, 77, 161 (2001).

[33] A. V. Phelps, “Cross Sections and Swarm Coefficients for $\mathrm{H}^{+}, \mathrm{H}_{2}{ }^{+}, \mathrm{H}_{3}{ }^{+}, \mathrm{H}, \mathrm{H}_{2}$, and $\mathrm{H}^{-}$in $\mathrm{H}_{2}$ for Energies from $0.1 \mathrm{eV}$ to $10 \mathrm{keV”,} \mathrm{J.} \mathrm{Phys.} \mathrm{Chem.} \mathrm{Ref.} \mathrm{Data,} \mathrm{19,} 653$ (1990).

[34] C. Gorse, M. Capitelli, "Vibrational excitation and negative-ion production in magnetic multicusp hydrogen discharges”, Chem. Phys., 93, 1 (1985).

[35] P. Kae-Nune, J. Perrin, J. Jolly and J. Guillon, "Surface recombination probabilities of H on stainless steel, a-Si:H and oxidized silicon determined by threshold ionization mass spectrometry in $\mathrm{H}_{2}$ RF discharges”, Surf. Sci., 360, L495 (1996).

[36] K. Kim and M. E. Rudd, "Binary-encounter-dipole model for electron-impact ionization”, Phys. Rev. A, 50, 3954 (1994).

[37] R. K. Janev, D. Reiter, U. Samm, “Collision Processes in Low-Temperature Hydrogen Plasmas” Forschungszentrum Jülich Report, Jül-4105, Jülich, 2003.

[38] S. Chapman and T. G. Cowling, The Mathematical Theory of Non-Uniform Gases, $3^{\text {rd }}$ edition, Cambridge University Press, 1991.

[39] A. V. Eletskii, “Elementary processes in gases and plasmas” in Handbook of Physical Quantities, ed. I. S. Grigoriev and E. Z. Meilikhov (Boca Raton, FL: CRC Press) pp 489-518 (table 18.11, p 498), 1997.

[40] C. Gorse, R. Celiberto, M. Cacciatore, A. Laganà and M. Capitelli, "From dynamics to modeling of plasma complex systems. negative ion $\left(\mathrm{H}^{-}\right)$sources”, Chem. Phys., 161, 211 (1992).

[41] B. Chapman, Glow Discharge Processes, Wiley, New York, 1980.

[42] Z. Donkó, J. Schulze, B. G. Heil and U. Czarnetzki, "PIC simulations of the separate control of ion flux and energy in CCRF discharges via the electrical asymmetry effect", $J$. Phys. D: Appl. Phys., 42, 025205 (2009).

[43] J. Schulze, E. Schüngel, U. Czarnetzki, and Z. Donkó, “Optimization of the electrical asymmetry effect in dual-frequency capacitively coupled radio frequency discharges: Experiment, simulation, and model”, J. Appl. Phys., 106, 063307 (2009). 
[44] Z. Donkó, J. Schulze, U. Czarnetzki, and D. Luggenhölscher, "Self-excited nonlinear plasma series resonance oscillations in geometrically symmetric capacitively coupled radio frequency discharges”, Appl. Phys. Lett., 94, 131501 (2009).

[45] B. Bruneau, T. Gans, D. O’Connell, A. Greb, E. V. Johnson, and J.-P. Booth, "Strong Ionization Asymmetry in a Geometrically Symmetric Radio Frequency Capacitively Coupled Plasma Induced by Sawtooth Voltage Waveforms”, Phys. Rev. Lett., 114, 125002 (2015). 